\title{
Prescribing Warfarin to a Patient with Oesophageal Varices-A Case Report and Review of the Literature
}

\author{
Jayan George ${ }^{1, *(1)}$ and Hasan N. Haboubi ${ }^{2}$ \\ 1 General Surgical Department, Sheffield Teaching Hospitals NHS Foundation Trust, Herries Road, \\ Sheffield S5 7AU, UK \\ 2 Cancer Biomarkers Group, Swansea University, Singleton Park, Swansea SA2 8PP, UK; \\ h.n.y.haboubi@swansea.ac.uk \\ * Correspondence: jayan.george@aol.com; Tel.: +44-1142-434343; Fax: +44-1142-266986
}

Received: 29 August 2018; Accepted: 25 September 2018; Published: 28 September 2018

\begin{abstract}
We describe the case of a 42-year old man who presented with melaena. He was found to have bleeding varices during endoscopic investigation. Subsequent investigation revealed the aetiology to be a portal vein thrombosis (PVT) due to an underlying pro-coagulable state (Factor V Leiden). He was managed with cautious anticoagulation but suffered a life-threatening upper gastrointestinal bleed that was not amenable to endoscopic treatment or transjugular intrahepatic portosystemic shunting (TIPS). As such, the only therapeutic option involved the pursuit of surgical shunt operations. We review the literature regarding this atypical cause of GI-bleeding and discuss medical and surgical considerations for the management of such patients.
\end{abstract}

Keywords: Factor V Leiden; Gastrointestinal Hemorrhage; portal vein; portosystemic shunt; anticoagulation

\section{Introduction}

Portal vein thrombosis (PVT) is thrombosis of that which develops in the trunk of the portal vein. It can involve intrahepatic branches of the portal vein due to local hepatic pathology or extra-hepatic tributaries such as the splenic vein and superior or inferior mesenteric veins [1]. The first case was described in 1868 [2]. PVT can be a partial or complete occlusion of the main trunk of the portal vein. The prevalence of PVT in compensated liver disease has been reported to be $0.6-16 \%[1,3,4]$. The management of these can be complex. We report our experience of a patient presenting with severe pancreatitis who later developed PVT and review the complexities of a case where shunt procedures cannot easily be performed due to absence of thrombus-free vessels.

\section{Case Presentation}

A 42-year-old Caucasian gentleman with no significant past medical or family history presented to the emergency department with epigastric abdominal pain, nausea and vomiting. He was investigated and found to have acute pancreatitis and was at this stage transferred to Intensive Care for further management. Subsequent investigations revealed that he had pancreatic necrosis and he was started on insulin therapy and Creon supplementation.

Two years later, he presented with swelling in the left calf and this was found to have a deep vein thrombosis (DVT), treated with warfarin anticoagulation for 3-months.

A further one-year later, he was admitted with abdominal pain, nausea, and melaena. At the time he was also found to have a distended abdomen. He underwent oesophagogastroduodenoscopy, which revealed large oesophageal varices for which band ligation therapy was administered. Computerised Tomography (CT) scanning of his abdomen scan during this admission revealed a thrombus in the 
mesenteric vein and portal vein as well as an oedematous colon (Figure 1) and a non-cirrhotic liver. Thrombophilia blood test screening revealed him to be heterozygous for Factor V Leiden deficiency.

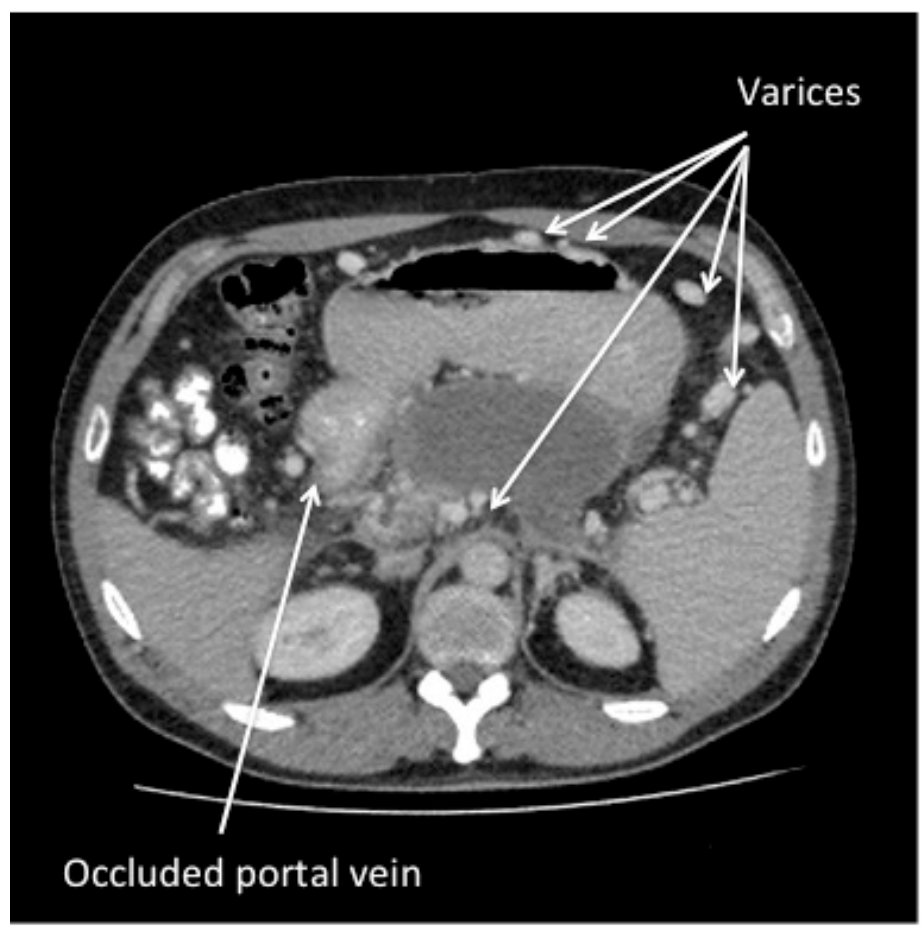

Figure 1. CT image showing an occluded portal vein and the presence of numerous collateral vessels (varices).

He was treated with the non-selective B-blocker propranolol to reduce portal pressures [5]. He continued to have regular surveillance endoscopies. Subsequently, aspirin therapy was commenced by the haematology team to reduce the risk of further thrombus formation whilst balancing the risk of bleeding. Later that year, he was admitted with left leg swelling and a DVT was confirmed and he was restarted on warfarin.

Four months later, he was admitted with significant haematemesis, vomiting approximately $1.5 \mathrm{~L}$ of blood. He was haemodynamically unstable and thus intubated and managed in Intensive Care with a blood transfusion, Sengstaken-Blakemore tube, the vasopressin analogue terlipressin and airway support [5]. Subsequent endoscopy revealed bleeding gastric fundal varices that did not respond to endoscopic sclerotherapy with cyanoacrylate injection [5].

A CT scan showed further extension of the thrombus (Figure 2) and, after discussion with a quaternary centre, the Sengstaken Blakemore was maintained until the patient could undergo a surgical shunt. Anatomical considerations (thrombus in the portal, splenic and mesenteric veins) made this technically difficult and following initial stabilisation, splenectomy with oesophageal devascularisation was considered the best alternative treatment. The patient suffered a further massive haemorrhage and, despite resuscitative efforts, died from bleeding before they could perform the procedure.

Ethics and Consent: Consent was gained directly from the patient's next of kin. As per Abertawe Bro Morganwwg University Health Board Research and Development (ABMU R\&D) policy, no additional ethical approval was required. 


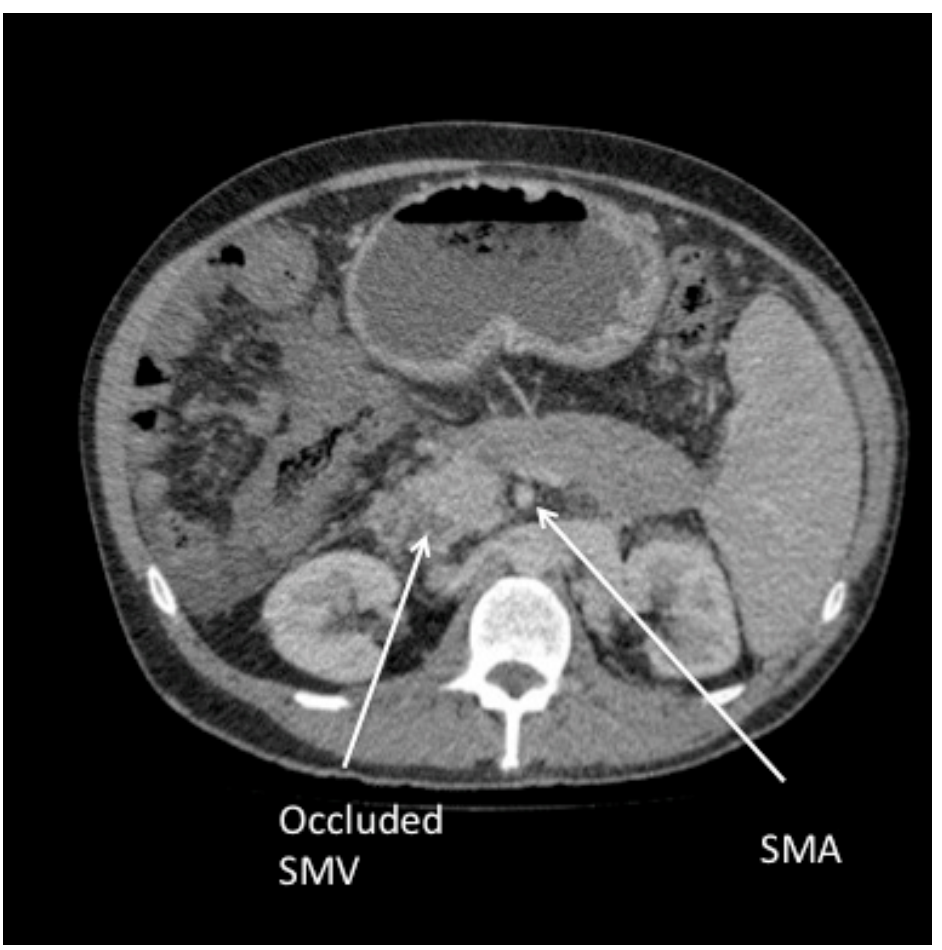

Figure 2. CT image showing extension of thrombus into the superior mesenteric vein (SMV) adjacent to the superior mesenteric artery (SMA).

\section{Discussion}

PVT has a multitude of causes summarised in Table 1 [6]. The commonest cause is secondary to cirrhosis, but non-cirrhotic extrahepatic PVT presentation is quite variable (due to vague symptom onset). Bleeding due to portal hypertension and the development of oesophageal varices is seen in up to $30 \%$ of such cases [7].

Table 1. Summarising the pathogenesis and aetiology of PVT.

\begin{tabular}{|c|c|}
\hline Pathogenesis & Aetiology \\
\hline \multirow{7}{*}{ Local inflammation } & Local inflammation including: \\
\hline & - $\quad$ Pancreatitis \\
\hline & - $\quad$ Cholecystitis \\
\hline & - $\quad$ Liver abscess \\
\hline & - Cirrhosis \\
\hline & - $\quad$ Hepatocellular cancer \\
\hline & - $\quad$ Pancreatic cancer \\
\hline $\begin{array}{l}\text { Local trauma/injury } \\
\text { (Direct damage to portal vein) }\end{array}$ & Abdominal trauma \\
\hline \multirow{6}{*}{ Prothrombotic disorders } & - $\quad$ Factor V Leiden \\
\hline & - $\quad$ Protein C/S deficiency \\
\hline & Acquired: \\
\hline & Myeloproliferative disorders \\
\hline & - Anti-phosphospholipid syndrome \\
\hline & - $\quad$ Drug induced thrombosis (e.g., oral contraceptive pill) \\
\hline Physiological & Pregnancy \\
\hline
\end{tabular}


Managing these patients is difficult and dependent on chronicity of thrombus. The differentiation between acute and chronic PVT is aided by CT-evidence of portal collaterals, splenomegaly, or oesophageal varices.

Anticoagulation should ideally be initiated within the first month of symptoms to allow early decompression of the portal system and reduce the risk of variceal development and bleeding. Recanalisation decreases from $69 \%$ in the first week to $25 \%$ in the second [8]. Recanalisation is less likely if extensive thrombosis or underlying prothrombotic disorder [9]. Most portal veins recanalise between 4-6 months and, therefore, patients should remain on anticoagulation for 6-months [10,11].

Long-term anticoagulation may be recommended for those with recurrent thrombosis, family history, or underlying prothrombotic disorders. Whilst controversial, anticoagulation does not appear to increase the risk or severity of bleeding in patients with known varices, although a more cautious approach should be considered if varices are large-the only significant predictor for bleeding [6].

Active variceal patients should be treated endoscopically in the first instance, which can produce spontaneous shunt formation in up to $40 \%$ of patients, which, in turn, serves to protect from further bleeding [6]. Whilst transjugular intrahepatic portosystemic shunt (TIPS) is sometimes useful to manage difficult to control bleeding, its efficacy is questionable in cannulating blocked portal veins.

If these approaches fail, then the patient usually requires specialist input and bypass (shunt) surgery. Numerous shunt options can be considered, being cognisant of patency of vessels. As such, particularly in patients with thrombus extending into the mesenteric vessels, management can be challenging, summarised in Table $2[6,12]$. Furthermore, given the rarity of presentation with non-cirrhotic portal venous occlusion with no vascular access to benefit from TIPS, experience with such shunt operations is often limited to a few specialist centres.

Table 2. Summary of management options of PVT.

\begin{tabular}{|c|c|c|}
\hline Shunt Option & Anatomical Connection & Clinical Consideration \\
\hline Radiological (TIPS) & Portal to Hepatic Vein & Requires patent portal vein. Rarely effective \\
\hline \multirow{4}{*}{$\begin{array}{c}\text { Non-selective Portosystemic } \\
\text { Shunt }\end{array}$} & Inferior Vena Cava & \multirow{2}{*}{$\begin{array}{l}\text { Caution in patients with ascites or } \\
\text { encephalopathy }\end{array}$} \\
\hline & - $\quad$ Mesocaval & \\
\hline & Right Atrium & \multirow[b]{2}{*}{$\begin{array}{l}\text { Useful in bypassing obstructed hepatic vein } \\
\text { or inferior vena cava }\end{array}$} \\
\hline & $\begin{array}{ll}- & \text { Mesoatrial } \\
- & \text { Portoatrial }\end{array}$ & \\
\hline \multirow{2}{*}{$\begin{array}{c}\text { Selective Portosystemic } \\
\text { Shunt }\end{array}$} & $\begin{array}{l}\text { Spleno-renal } \\
\text { (Splenic vein to renal vein) }\end{array}$ & \multirow{2}{*}{$\begin{array}{l}\text { Requires patent splenic vein. } \\
\text { Low risk of encephalopathy }\end{array}$} \\
\hline & - $\quad$ May include splenectomy & \\
\hline \multicolumn{2}{|l|}{$\begin{array}{l}\text { Oesophageal transection } \pm \\
\text { splenectomy }\end{array}$} & $\begin{array}{l}\text { Extensive thrombosis. Life threatening bleed. } \\
\text { Better outcome in patients without } \\
\text { underlying myeloproliferative disorder }\end{array}$ \\
\hline \multicolumn{2}{|l|}{ Liver Transplant } & $\begin{array}{l}\text { Underlying cirrhosis or local damage to PVT. } \\
\text { Consider if conservative measures/shunt } \\
\text { surgery fail }\end{array}$ \\
\hline
\end{tabular}

Whilst variceal bleeding is commonly associated with underlying cirrhosis, other aetiologies such as non-cirrhotic portal vein thrombosis should be considered in the compensated liver patient. Portal vein thrombosis can affect anywhere between $0.6-16 \%$ of such patients, and most commonly presents with variceal bleeding $(30 \%)$, although atypical abdominal pain may also be seen. Recanalisation of the portal vein most commonly occurs in the first week and in association with reversible conditions such as pancreatitis. Chronic PVT is more commonly associated with underlying pro-thrombotic states. In the stable, non-bleeding patient, anticoagulation with warfarin can be considered, even if varices are present. Surgical bypass procedures should be considered in the 
bleeding patient with selection of appropriate shunt procedure guided by CT or MRI angiography to assess patency of surrounding vessels. In the absence of patent vessels to facilitate such bypass shunts, splenectomy with or without oesophageal devascularisation can be considered in patients with no other surgical options who are at risk of exsanguinating. Whilst splenectomy is often reserved for patients with isolated splenic vein thrombosis, it should be considered at an early stage as a life-saving salvage approach to patients with bleeding varices from multivessel extrahepatic thrombosis as it can reduce flow and thereby possibly reduce portal pressures [13].

Author Contributions: J.G.: Developing, proofing the manuscript and editing the images. H.N.H.: Developing, proofing the manuscript, concept development and editing the images.

Conflicts of Interest: The authors declare no conflict of interest.

\section{References}

1. Chawla, Y.K.; Bodh, V. Portal Vein Thrombosis. J. Clin. Exp. Hepatol. 2015, 5, 22-40. [CrossRef] [PubMed]

2. Balfour, G.W.; Stewart, T.G. Case of enlarged spleen complicated with ascites, both as upon varicose dilatation and thrombosis of the portal vein. Edin. Med. J. 1869, 14, 589.

3. Okuda, K.; Ohnishi, K.; Kimura, K.; Shoichi, M.; Masatoshi, S.; Nobuaki, G.; Hirotaka, M.; Motohide, T.; Noriaki, S.; Takashi, S.; et al. Incidence of portal vein thrombosis in liver cirrhosis. An angiographic study in 708 patients. Gastroenterology 1985, 89, 279-286. [CrossRef]

4. Gaiani, S.; Bolondi, L.; Li Bassi, S.; Zironi, G.; Siringo, S.; Barbara, L. Prevalence of spontaneous hepatofugal portal flow in liver cirrhosis. Clinical and endoscopic correlation in 228 patients. Gastroenterology 1991, 100, 160-167. [CrossRef]

5. Tripathi, D.; Stanley, A.J.; Hayes, P.C.; Patch, D.; Millson, C.; Mehrzad, H.; Austin, A.; Ferguson, J.W.; Olliff, S.P.; Hudson, M.; et al. U.K. guidelines on the management of variceal haemorrhage in cirrhotic patients. Gut 2015, 64, 1680-1704. [CrossRef] [PubMed]

6. Chawla, Y.; Duseja, A.; Dhiman, R.K. Review article: The modern management of portal vein thrombosis. Aliment. Pharmacol. Ther. 2009, 30, 881-894. [CrossRef] [PubMed]

7. Laine, L. Upper gastrointestinal tract hemorrhage. West. J. Med. 1991, 155, 274-279. [PubMed]

8. Turnes, J.; García-Pagán, J.C.; González, M.; Aracil, C.; Calleja, J.L.; Ripoll, C.; Abraldes, J.G.; Bañares, R.; Villanueva, C.; Albillos, A.; et al. Portal hypertension-related complications after acute portal vein thrombosis: Impact of early anticoagulation. Clin. Gastroenterol. Hepatol. 2008, 6, 1412-1417. [CrossRef] [PubMed]

9. Amitrano, L.; Guardascione, M.A.; Scaglione, M.; Pezzullo, L.; Sangiuliano, N.; Armellino, M.F.; Manguso, F.; Margaglione, M.; Ames, P.R.J.; Iannaccone, L.; et al. Prognostic factors in noncirrhotic patients with splanchnic vein thromboses. Am. J. Gastroenterol. 2007, 102, 2464-2470. [CrossRef] [PubMed]

10. Sarin, S.K.; Sollano, J.D.; Chawla, Y.K.; Amarapurkar, D.; Hamid, S.; Hashizume, M.; Jafri, W.; Kumar, A.; Kudo, M.; Lesmana, L.A.; et al. Consensus on extra-hepatic portal vein obstruction. Liver Int. 2006, 26, 512-519. [CrossRef] [PubMed]

11. de Franchis, R. Evolving consensus in portal hypertension. Report of the Baveno IV consensus workshop on methodology of diagnosis and therapy in portal hypertension. J. Hepatol. 2005, 43, 167-176. [CrossRef] [PubMed]

12. Taslakian, B.; Faraj, W.; Khalife, M.; Al-Kutoubi, A.; El-Merhi, F.; Saade, C.; Hallal, A.; Haydar, A. Assessment of surgical portosystemic shunts and associated complications: The diagnostic and therapeutic role of radiologists. Eur. J. Radiol. 2015, 84, 1525-1539. [CrossRef] [PubMed]

13. Menasherian-Yaccobe, L.; Jaqua, N.T.; Kenny, P. Successful treatment of bleeding gastric varices with splenectomy in a patient with splenic, portal, and mesenteric thromboses. Case Rep. Surg. 2013, 2013, 273531. [CrossRef] [PubMed]

(C) 2018 by the authors. Licensee MDPI, Basel, Switzerland. This article is an open access article distributed under the terms and conditions of the Creative Commons Attribution (CC BY) license (http:/ / creativecommons.org/licenses/by/4.0/). 